\title{
Uma nova espécie de Pera (Peraceae) endêmica de Manaus, Amazonas, Brasil
}

\author{
A new species of Pera (Peraceae) endemic to Manaus, Amazonas, Brazil
}

\author{
Narcísio Costa Bigio ${ }^{1} \&$ Ricardo de S. Secco ${ }^{2}$
}

\begin{abstract}
Resumo
Pera manausensis Bigio \& Secco, uma nova espécie de Euphorbiaceae endêmica de Manaus, Amazonas, é descrita e ilustrada. Esta espécie é afim de P. decipiens Muell. Arg., P. bicolor (Klotzsch) Muell. Arg. e P. tomentosa (Benth.) Muell. Arg., mas separa-se destas por ser a única a apresentar face abaxial da folha com tricomas lepidoto-estrelados, emaranhados, flores estaminadas com cálice 3-lobado e pistilódio filiforme, e flores pistiladas com ovário tomentoso, estigma 3-lobado, lobos bipartidos e estaminódios sepalóides, filiformes. Discussões sobre as afinidades do novo táxon, bem como uma chave para separação das espécies mais próximas, são apresentadas.

Palavras-chave: Amazônia brasileira, Euphorbiaceae, espécie nova.
\end{abstract}

\begin{abstract}
Pera manausensis Bigio \& Secco, a new species of Euphorbiaceae endemic to Manaus, Amazonas, is described and illustrated. This species is closely related to P. decipiens Muell. Arg., P. bicolor (Klotzsch) Muell. Arg. and P. tomentosa (Benth.) Muell. Arg., but can be recognized by the following: leaf abaxial surface with entangled, lepidote-stellate trichomes; staminate flowers with calyx 3-lobed and pistillodium filiform; pistillate flowers with tomentose ovary, stigma 3-lobed, lobes bifid, and staminodia sepaloid, filiform. The affinities of the new taxon are discussed and a key to separate closely related species is presented.

Key words: Brazilian Amazon, Euphorbiaceae, new species.
\end{abstract}

\section{Introdução}

Pera Mutis é um gênero endêmico dos Neotrópicos (Gordillo \& Morrone 2005) com aproximadamente 30 espécies (Webster 1994; Gillespie \& Armbruster 1997), ocorrendo desde Cuba e América Central até sul do Brasil. Sua maior concentração encontra-se na Amazônia (Webster 1994), sendo que 13 especies ocorrem na Amazônia brasileira (Bigio 2009).

As espécies de Pera são árvores e arbustos dióicos, raramente monóicos (em $P$. distichophylla (Mart.) Baill. e P. androgyna Rizzini), com uma característica morfológica peculiar das Peraceae, os pseudantos axilares, que consistem de flores pequenas envolvidas por uma bráctea involucral vistosa (de cores amarela, creme, branca ou, às vezes, avermelhada), perfumada e mais ou menos globosa; na base do invólucro há uma ou duas bractéolas. Duas espécies têm usos populares: P. glabrata (Schott) Baill. é utilizada no Brasil para a produção de tamancos (Lorenzi 1992), e P. benensis Rusby no tratamento da Leishmaniose cutânea, pelos índios Chimane, da Bolívia (Fournet et al. 1992).

O trabalho mais completo sobre Pera é de Pax \& Hoffmann (1919), porém muitas outras espécies foram posteriormente publicadas, e também muitos sinônimos foram estabelecidos (Bigio 2009). Os trabalhos mais recentes são os de Gillespie \& Ambruster (1997), tratando cinco espécies da Flora da Guiana; Gillespie (1999), que trata sucintamente seis espécies da Guiana venezuelana, e Bigio (2009), que revisou as espécies da Amazônia brasileira.

A circunscrição de Euphorbiaceae vem passando por alterações nos último anos e, consequentemente, o posicionamento de Pera tem sido alterado. Webster (1994) considerou esse gênero em Euphorbiaceae, subfamília Acalyphoideae. Esse conceito foi corroborado pelo estudo da anatomia da madeira (Hayden \& Hayden 2000). Já os estudos de pólen (Nowicke et al. 1998; Nowicke \& Takahashi

${ }_{1}^{1}$ Universidade Federal de Rondônia, Depto. Biologia, Campus José RibeiroFilho, BR 364, km 9,5, 76800-000, Porto Velho, RO, Brasil. narcisio@gmail.com-Professor/Curador.

${ }^{2}$ Museu Paraense Emílio Goeldi, Depto. Botânica. C.P. 399, 66040-170, Belém, PA, Brasil. rsecco@museu-goeldi.br-Pesquisador/Curador, Bolsista CNPq. 
2002) e dos óvulos (Tokuoka \& Tobe 2003) sugeriram outro posicionamento, em uma possível nova subfamília de Euphorbiaceae não designada pelos autores. Isto foi comprovado nos estudos filogenéticos de Wurdack et al. (2005), que posicionou Pera na subfamília Peroideae, juntamente com Chaetocarpus Thwaites, Clutia L., Pogonophora Miers ex Bentham e Trigonopleura Hook.f. Stevens (2001) e Souza \& Lorenzi (2008), baseados no sistema APG II (2003) e nas atualizações de Stevens (2001), concordaram que Pera pertença à Peraceae, mas não isoladamente, e sim com os demais quatro gêneros considerados por Wurdack et al. (2005). Isto seria justificado pelo fato de características moleculares indicarem que Raflesiaceae estaria incluída entre as Peroideae e as demais Euphorbiaceae (senso Wurdack et al., 2005), que formariam um grupo polifilético. De acordo com APG III (2009), o reconhecimento de Peraceae Klotzsch (1859) seria necessário para manter Euphorbiaceae como um grupo monofilético, entretanto, devido à necessidade de estudos adicionais, não reconheceram Peraceae como família. Neste trabalho manteve-se Pera em Peraceae, de acordo com o que foi decidido pela equipe responsável pela família Euphorbiaceae no projeto da Lista de Espécies da Flora do Brasil.

No estudo das coleções amazônicas de Pera, encontrou-se três espécimes procedentes de Manaus, Amazonas, que se diferenciavam das espécies até então conhecidas, o que levou à proposição de um novo táxon, que é descrito, ilustrado e comentado, a seguir.

\section{Material e Métodos}

Como parte da revisão das espécies de Pera ocorrentes na Amazônia brasileira, e tendo como base as exsicatas (incluindo alguns tipos) depositadas nos herbários IAN, INPA, MG, R, RB, SP, UB e UFMT e fotografias dos tipos procedentes das coleções de F, G, IAN, K, L, NY e P.

\section{Resultados e Discussão}

Pera manausensis Bigio \& Secco, sp. nov. Tipo: BRASIL. AMAZONAS: Manaus, Reserva Ducke, Estrada Manaus-Itacoatiara km 26, entrada do alojamento-torre km 35, 22.IV.1995, fl., F.A. Vicentini et al. 1058 (holótipo MG!; isótipos INPA!, SP!, $\mathrm{UB}$ !).

Fig. $1 \mathrm{a}-\mathrm{m}$

Arbor. Folia in pagina abaxiali denso indumento trichomatum lepidoto-stellatorum obtecta, nervis prominentibus. Inflorescentiae involucro per anthesin longitudinaliter aperiuntur. Flores staminati calyce 3-lobato, campanulato trichomatibus simplicibus sparsis, pistilloidio 1 filiformi. Flores pistillati ovario globoso tomentoso, trichomatibus simplicibus obtecto, stigmate 3 lobato, bipartito, staminodio sepaloideo centrali 1 vel 2, deformi et staminodio 1 extus filiformi.

Árvore dióica ca. $25 \mathrm{~m}$ alt. $\times 30 \mathrm{~cm}$ diâm. Ramos com indumento de tricomas estrelado-lepidotos. Folhas alternas, peninérveas, 8-12,5 × 4,5-6,5 cm, elíptico-oblongas, coriáceas, margens inteiras, base cuneada, ápice obtuso a arredondado; face adaxial com tricomas estrelados apenas na nervura principal; face abaxial com denso indumento de tricomas lepidoto-estrelados, emaranhados, nervuras proeminentes, glândulas ausentes; pecíolo 1-1,5 cm compr., canaliculado, piloso, com tricomas lepidotos. Inflorescências pistiladas em pseudantos fasciculados, com denso indumento de tricomas lepidotoestrelados, pedúnculo com tricomas lepidotoestrelados, bractéolas 2 na base do invólucro, orbiculares, opostas, com denso indumento de tricomas lepidoto-estrelados; invólucro das flores estaminadas 3-5 mm diâm., pedúnculo 1,2-5 mm compr., bractéolas ca. 1 mm diâm.; invólucro das flores pistiladas abrindo-se na antese através de uma fenda longitudinal até a metade, 5-6 mm diâm., pedúnculo 0,5-1 cm compr., bractéolas 2-3 mm diâm. Flores estaminadas 3, sésseis, pétalas ausentes, cálice 3lobado, campanulado, lóbulos 0,5-1,3 mm compr., margens laceradas, com tricomas simples, esparsos; estames 3 ou 4 por flor, 1,5-2,5 mm compr., concrescidos na base, filetes $0,5-1 \mathrm{~mm}$, glabros, anteras 1-1,5 mm compr., rimosas, apicifixas, pistilódio presente ca. $1 \mathrm{~mm}$ compr., filiforme, com tricomas simples, esparsos. Flores pistiladas 4, pedicelo 0,61,2 mm compr., aclamídeas, ovário 4-5 mm diâm., globoso, tomentoso, tricomas simples, óvulo 1 por lóculo, estilete séssil a subséssil, ca. 0,2 mm compr., estigma 3-lobado, lobos bipartidos, 3-4 mm compr., face inferior tomentosa, face superior glabra, papilosa, estaminódios sepalóides 1 ou 2, centrais, disformes, lacerados, 1-2 $\times 0,3-1,2 \mathrm{~mm}$, com indumento esparso de tricomas simples, estaminódio filiforme 1, com 11,2 mm compr., tricomas simples. Frutos 1-1,2×1-1,2 $\mathrm{cm}$, globosos, mericarpos 3 , mesocarpo liso, com indumento tomentoso, pedicelo 5-7 $\mathrm{mm}$ compr. Sementes imaturas.

Endêmica da Amazônia Central, Manaus, estado do Amazonas, Brasil. Floresce de junho a novembro. Frutifica em dezembro. 


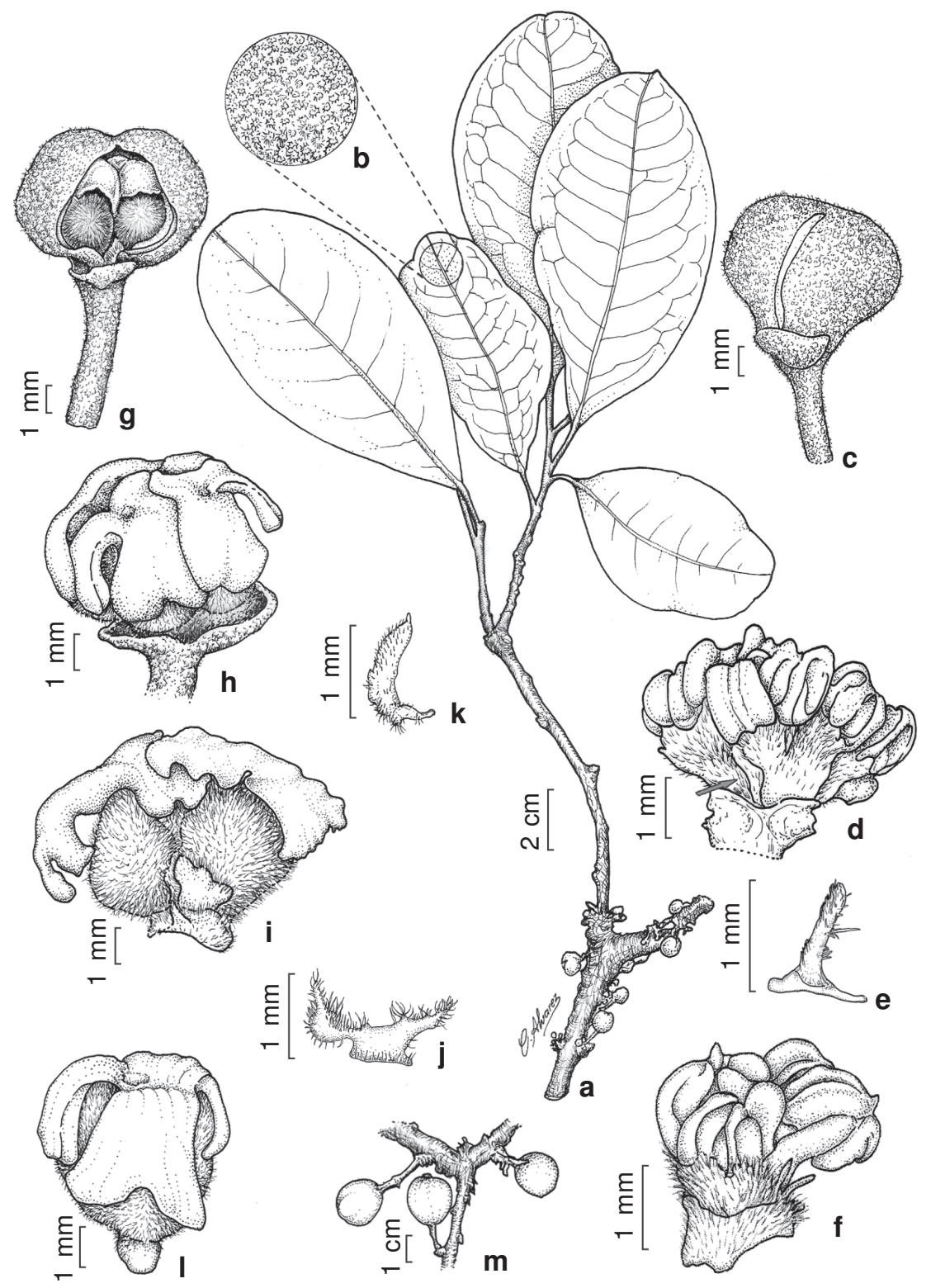

Figura 1 - Pera manausensis Bigio \& Secco - a. ramo com inflorescências; b. detalhe do denso indumento de tricomas lepidoto-estrelados na face abaxial da folha; c. inflorescência estaminada abrindo-se por uma fenda longitudinal na antese; d. três flores estaminadas, com invólucro removido e com um pistilódio externo (seta); e. detalhe do pistilódio filiforme; f. detalhe da flor estaminada, com indumento de tricomas simples no cálice; g. inflorescência pistilada em pseudanto, com uma fenda longitudinal na antese; h. quatro flores pistiladas, com invólucro removido, brácteas opostas na base; i. duas flores pistiladas, estaminódio sepalóide central e o estaminódio filiforme externo; j. detalhe do estaminódio sepalóide; $\mathrm{k}$. detalhe do estaminódio filiforme externo; 1 . flor pistilada com estigma 3-lobado e lobos bipartidos. m. frutos. (a-b,g-1 Vicentini et al. 1058; c-f Oliveira et al. 245; m Costa et al. 433).

Figure 1 - Pera manausensis Bigio \& Secco - a. branch with pistillate inflorescence; b. detail of dense indument of lepidote-stellate trichomes on the lower surface; $c$. staminate inflorescence opening by a longitudinal opening at anthesis; d. three staminate flowers without the involucral bract and one external pistilodium (arrow); e. detail of the filiform pistillodium; f. detail of staminate flower with indument of simple trichomes on the calyx; g. pistillate inflorescence with a longitudinal opening at anthesis; h. four pistillate flowers without the involucral bract, opposite bracteolea at the base; i. two pistillate flowers, central sepaloid staminodium and the external filiform staminodium; j. detail of the sepaloid staminodium; k. detail of the filiform staminodium; 1. pistillate flower with 3lobed stigma with bifid lobes. m. fruits. (a-b,g-1 Vicentini et al. 1058; c-f Oliveira et al. 245; m Costa et al. 433). 
Material examinado: BRASIL. AMAZONAS: Manaus, Reserva Ducke, Estrada Manaus-Itacoatiara km 26, estrada alojamento-torre km 35, 5.XII.1995, fr., M.A.S. Costa et al. 433 (MG); Distrito Agropecuário, $90 \mathrm{~km} \mathrm{NNE} \mathrm{de}$ Manaus, Reserva 1501 km 41, projeto Dinâmica Biológica de Fragmentos Florestais, 2²4'26”S, 5943'40”W, 21.XI.1991 (m), A.A. Oliveira et al. 245 (INPA).

Os dois espécimes (Vicentini et al. $1058 \mathrm{e}$ Costa et al. 433), provenientes da Reserva Ducke, foram coletados da mesma árvore, que está marcada com o número 3304-11 e apresentava-se identificada como Pera schomburgkiana (Benth.) Müll. Arg. Esta espécie um é sinônimo de $P$. bicolor (Kloztsch) Müll. Arg. Desta forma, são conhecidos somente dois indivíduos contendo flores, um com flor pistilada (da Reserva Ducke) e outro com flor estaminada (do Distrito Agropecuário de Manaus).

$O$ indumento da face abaxial das folhas de Pera manausensis é similar ao de P. decipiens Müll. Arg., já que ambas possuem tricomas lepidotosestrelados. Mas separam-se prontamente, pois $P$. manausensis tem ovário com indumento tomentoso, de tricomas simples, enquanto em $P$. decipiens o ovário é piriforme, com tricomas lepidotoestrelados; além disso, a nova espécie tem nervuras mais proeminentes que em $P$. decipiens.

A flor pistilada da nova espécie assemelha-se muito a de Pera bicolor, já que em ambas o ovário é tomentoso, com estigma 3-lobado, lobos bipartidos, além da presença de estaminódios, devendo ser por isso a identificação equivocada como $P$. schomburgkiana. Mas $P$. manausensis possui folhas com tricomas lepidoto-estrelados na face abaxial, cálice das flores estaminadas 3-lobado, campanulado e pistilódio filiforme; já $P$. bicolor tem a face abaxial das folhas com tricomas estrelados, cálice das flores estaminadas lacerado, disforme e ausência de pistilódio.

A presença de ovário tomentoso também aproxima Pera manausensis de $P$. tomentosa. Mas desta se separa facilmente pela face abaxial das folhas com indumento de tricomas lepidotoestrelados, flores pistiladas com estigma 3-lobado, lobos bipartidos e flores estaminadas com pistilódio filiforme. Em P. tomentosa a face abaxial das folhas possui denso indumento de tricomas estrelados, flores pistiladas com estigma 3-lobado, lobos inteiros e ausência de pistilódio.

Por ter o invólucro da inflorescência abrindose através de uma fenda longitudinal na antese, flores estaminadas com pistilódio e flores pistiladas com estaminódios, Pera manausensis deve ser posicionada em Pera sect. Neopera Griseb.

Pera manausensis é a segunda espécie endêmica conhecida para a região de Manaus, a primeira é Pera pulchrifolia Ducke, que pode ser facilmente reconhecida pelas folhas opostas.

\section{Chave para identificação das espécies próximas de Pera manausensis}

1. Folhas com esparso indumento de tricomas estrelados, nunca emaranhados; flores estaminadas com cálice irregular, laciniado P. bicolor

1'. Folhas com denso indumento de tricomas lepidoto-estrelados ou estrelados emaranhados; flores estaminadas com cálice regular, 3-lobado.

2. Flores pistiladas com 1 ou 2 estaminódios sepalóides; estigma com lobos bipartidos

2'. Flores pistiladas com 3 estaminódios sepalóides; estigma com lobos inteiros.

3. Folhas com denso indumento de tricomas lepidoto-estrelados; flores pistiladas pediceladas; ovário piriforme, com denso indumento de tricomas lepidotos ....................... P. decipiens

3'. Folhas com indumento tomentoso de tricomas estrelados; flores pistiladas sésseis; ovário globoso, com indumento tomentoso de tricomas estrelados P. tomentosa

\section{Agradecimentos}

Os autores agradecem ao CNPq as bolsas de mestrado e de produtividade concedidas ao autor e coautor, respectivamente; aos curadores dos herbários consultados; ao desenhista Carlos Alvarez, a espetacular ilustração; ao Dr. William Rodrigues, da Universidade Federal do Paraná, a tradução da diagnose para o latim. Agradecimentos especiais ao Dr. Alain Chautems e Dr. Laurent Gautier, do Herbário G, e à Mme. Caroline Loup, do Herbário $\mathrm{P}$, as fotografias de tipos disponibilizadas, que foram essenciais para a definição do novo táxon. 


\section{Referências}

APG II. 2003. An update of the Angiosperm Phylogeny Group classification for the orders and families of flowering plants: APG II. Botanical Journal of the Linnean Society 141: 399-436.

APG III. 2009. An update of the Angiosperm Phylogeny Group classification for the orders and families of floweringplants: APG III. Botanical Journal of the Linnean Society 161: 105-121.

Bigio, N.C. 2009. As espécies de Pera Mutis (Euphorbiaceae) na Amazônia Brasileira. Dissertação de Mestrado. Universidade Federal Rural da Amazônia, Belém. 117p.

Fournet, A.; Angelo, A.; Munoz, V.; Roblot, F.; Hocquemiller, R. \& Cave, A. 1992. Biological and chemical studies of Pera benensis, a Bolivian plant used in folk medicine as a treatment of cutaneous leishmaniosis. Journal of Ethnopharmacology 37: 159-164.

Gillespie, L.J. 1999. Pera. In: Webster, G.L.; Berry, P.E.; Armbruster, W.S.; Esser, H.J.; Gillespie, L.J.; Hayden, J.; Levin, G.A.; Secco, R.S. \& Heald, S.V . Euphorbiaceae. In: Steyermark, J.A.; Berry, P.E. \& Holst, B.K. (ed.). Flora of the Venezuelan Guayana. Vol. 5. Eriocaulaceae-Lentibulariaceae. Missouri Botanical Gardens Press, St. Louis. Pp. 186-191.

Gillespie, L.J. \& Armbruster, W.S. 1997. A Contribution to the Guianan flora: Dalechampia, Haematostemon, Omphalea, Pera, Plukenetia and Tragia (Euphorbiaceae) with notes on subfamily Acalyphoideae. Smithsonian Contributions to Botany 86: 1-48.

Gordillo, M.M. \& Morrone, J.J. 2005. Patrones de endemismo y disyunción de los géneros de Euphorbiaceae sensu lato: una análisis Panbiogeográfico. Boletín de la Sociedad Botánica de México 77: 21-33.

Hayden, W.J. \& Hayden, S.M. 2000. Wood anatomy of Acalyphoideae (Euphorbiaceae). IAWA 21: 213-235.

Klotzsch, J.F. 1859. Linne's natürliche Pflanzenklasse Tricoccae des Berliner Herbarium's im Allgemeinen und die natürlich Ordnung Euphorbiaceae insbesondere. Königlich Preussische Akademie der Wissenschaften zu Berlin. Pp. 236-254.

Lorenzi, H. 1992. Árvores brasileiras: manual de identificação e cultivo de plantas arbóreas e nativas do Brasil. Vol. 1. Plantarum, Nova Odessa. 109p.

Nowicke, J.W.; Takahashi, M.; Webster, G.L. 1998. Pollen morpholgy, exine structure and systematics of
Acalyphoideae (Euphorbiaceae) Part. 1 Tribes Clutieae (Clutia), Pogonophoreae (Pogonophora), Chaetocarpeae (Chaetocarpus, Trigonopleura), Pereae (Pera), Cheiloseae (Cheilosa, Neoscortecchinia), Erismantheae pro parte (Erismanthus, Moultonianthus), Dicoelieae (Dicoelia), Galearieae (Galearia, Microdesmis, Panda) and Ampereae (Amperea, Monotaxis). Review of Paleobotany and Palynology 102: 115-152.

Nowicke, J.W. \& Takahashi, M. 2002. Pollen morphology, exine structure and systematics of Acalyphoideae (Euphorbiaceae), Part 41 Tribes Acalypheae pro parte (Erythrococca, Claoxylon, Claoxylopsis, Mareya, Mareyopsis, Discoclaoxylon, Micrococca, Amyrea, Lobanilia, Mallotus, Deuteromallotus, Cordemoya, Cococceras, Trewia, Neotrewia, Rockinghamia, Octospermum, Acalypha, Lasiococca, Spathiostemon, Homonoia), Plukenetieae (Haematostemon, Astrococcus, Angostyles, Romanoa, Eleutherostigma, Plukenetia, Vigia, Cnesmone, Megistostigma, Sphaerostylis, Tragiella, Platygyna, Tragia, Acidoton, Pachystylidium, Dalechampia), Omphaleae (Omphalea), and discussion and summary of the complete subfamily. Review of Paleobotany and Palynology 121: 231-336.

Pax, F.A. \& Hoffmann, K. 1919. Euphorbiaceae-Pereae. In: Engler, A. (ed.). Das Pflanzenreich. Engelmann, Liepzig. Vol. 68: 1-14.

Souza, V.C. \& Lorenzi, H. 2008. Botânica sistemática: guia ilustrado para identificação das famílias de Angiospermas da flora brasileira, baseado em APG II. $2^{\mathrm{a}}$ ed. Instituto Plantarum, Nova Odessa. 704p.

Stevens, P.F. (2001 onwards). Angiosperm phylogeny website. Version 9, June 2008. Disponível em <http:/ /www.mobot.org/MOBOT/research/APweb/>. Acesso em 15 outubro 2008.

Tokuoka, T. \& Tobe, H. 2003. Ovules and seeds in Acalyphoideae (Euphorbiaceae): structure and systematic implications. Journal of Plant Research 116: 355-380.

Webster, G.L. 1994. Synopsis of the genera and suprageneric taxa of Euphorbiaceae. Annals of the Missouri Botanical Garden 81: 33-144.

Wurdack, K.J.; Hoffmann, P. \& Chase, M.W. 2005. Molecular phylogenetic analysis of uniovulate Euphorbiaceae (Euphorbiaceae sensu stricto) using plastid $r b c \mathrm{~L}$ and $t r n \mathrm{~L}-\mathrm{F}$ DNA sequences. American Journal of Botany 92: 1397-1420. 